\title{
Mine waste characterisation - complexities with assessing the physical properties of rock
}

\author{
S Mackenzie Mine Earth Pty Ltd, Australia \\ N de Kever Mine Earth Pty Ltd, Australia \\ E Smedley Mine Earth Pty Ltd, Australia \\ S Gregory Mine Earth Pty Ltd, Australia
}

\begin{abstract}
The aim of mine waste characterisation is to assess the geochemical and physical properties of rock in order to identify deleterious or beneficial materials. Mine waste geochemistry is generally well understood and there are accepted procedures to assess the geochemical properties of rock. Predicting the physical properties of mine waste is more difficult and practitioners are achieving mixed results with varied methods.

Routine soil science techniques are commonly applied to assess the physical properties of rock. Such techniques measure the resultant properties of rock, without considering the geological factors that control those properties. Such testwork results can be unreliable in predicting erosion potential of rock. Furthermore, practitioners may fail to develop a working appreciation of deposit scale geology prior to sample collection and testwork. In many cases such limitations result in incorrect predictions relating to the physical properties of rock.

There are five geological factors that control the physical properties of rock: petrology/lithology, alteration, mineralogy, weathering and structural deformation. The interplay between these factors in determining the as-dumped erosion stability of rock on a mining landform can be complex.

This paper considers the geological factors that control the physical properties of rock, the effectiveness of current assessment methods and opportunities to advance current practice. Field data is used to support observations where applicable.
\end{abstract}

\section{Introduction}

The aim of a mine waste characterisation program is to assess the geochemical and physical properties of mine waste to identify deleterious or beneficial materials. Successful mine waste characterisation is of paramount importance in light of the potential environmental, social and financial impacts from mining landforms constructed from geochemically reactive or erosive mine waste (Smedley et al. 2014).

From a mine closure perspective, mine waste can exhibit deleterious geochemical properties (including multi-elemental enrichments, acid-formation potential) or beneficial geochemical properties (such as favourable plant growth properties). Mine waste can also exhibit deleterious physical properties (such as erosion potential) or beneficial physical properties (including durability or low infiltration properties).

Mine waste geochemistry is generally well understood and substantial effort has been devoted to establishing accepted procedures to assess geochemical properties. Predicting the physical properties of mine waste is more difficult; there are less universal procedures for assessing physical properties and practitioners are achieving mixed results with varied methods.

This paper explores the factors that control the physical properties of rock, the effectiveness of current assessment methods and opportunities to advance current practice. In this paper, 'mine waste' refers to 'waste rock'. 


\section{Factors that control the physical properties of rock}

Five geological factors influence the physical properties of rock: petrology/lithology, alteration, mineralogy, weathering and structural deformation. Each of these factors is described in this section with examples where applicable.

It should be noted that mechanical disturbance during mining will also influence the as-dumped stability of rock. Various rock types will respond differently to drill, blast, load, haul, dump and doze activities - some may readily break down to a fine particle size whilst others may retain a relatively coarse fragment size. Segregation during dumping can also influence stability properties. Coarse rock can be preferentially distributed to the lower portion of a batter during dumping due to natural sorting (Figure 1). This can have implications for preserving coarse rock during batter reprofiling when finer rock from the top of the batter will be redistributed over coarser rock at the toe (Figure 2). Whilst important, the influence of mechanical disturbance will not be discussed further in this paper.

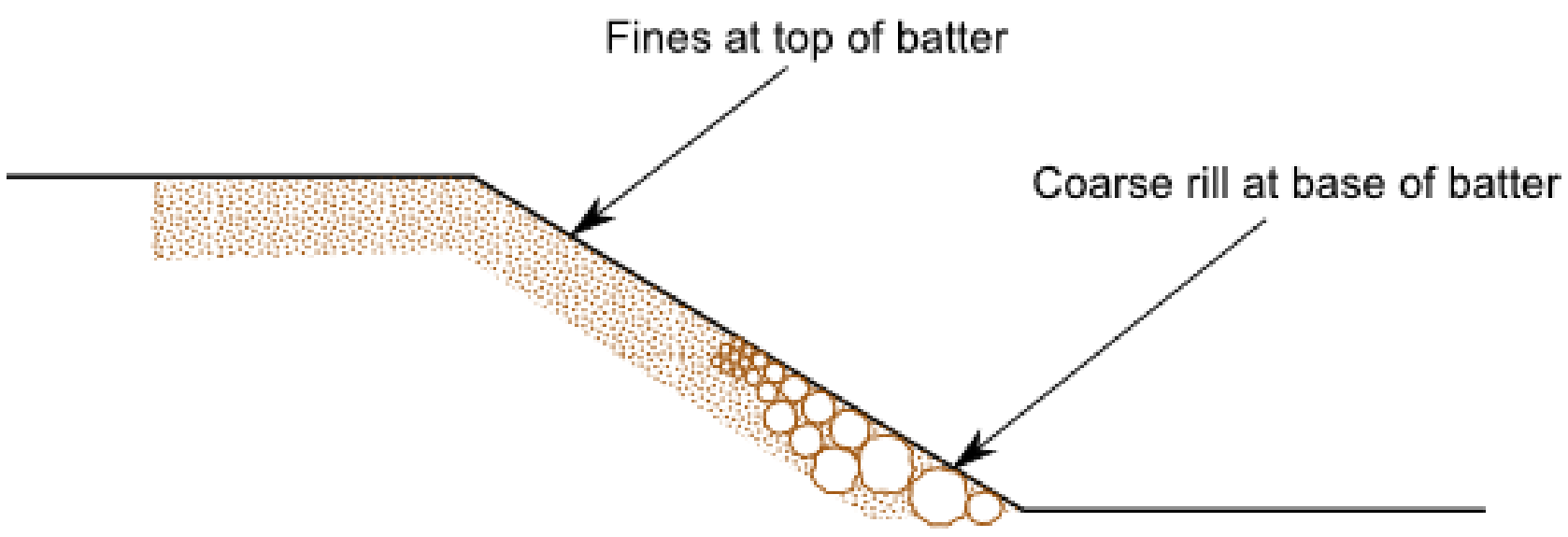

Figure 1 Typical particle size distribution on WRD batter

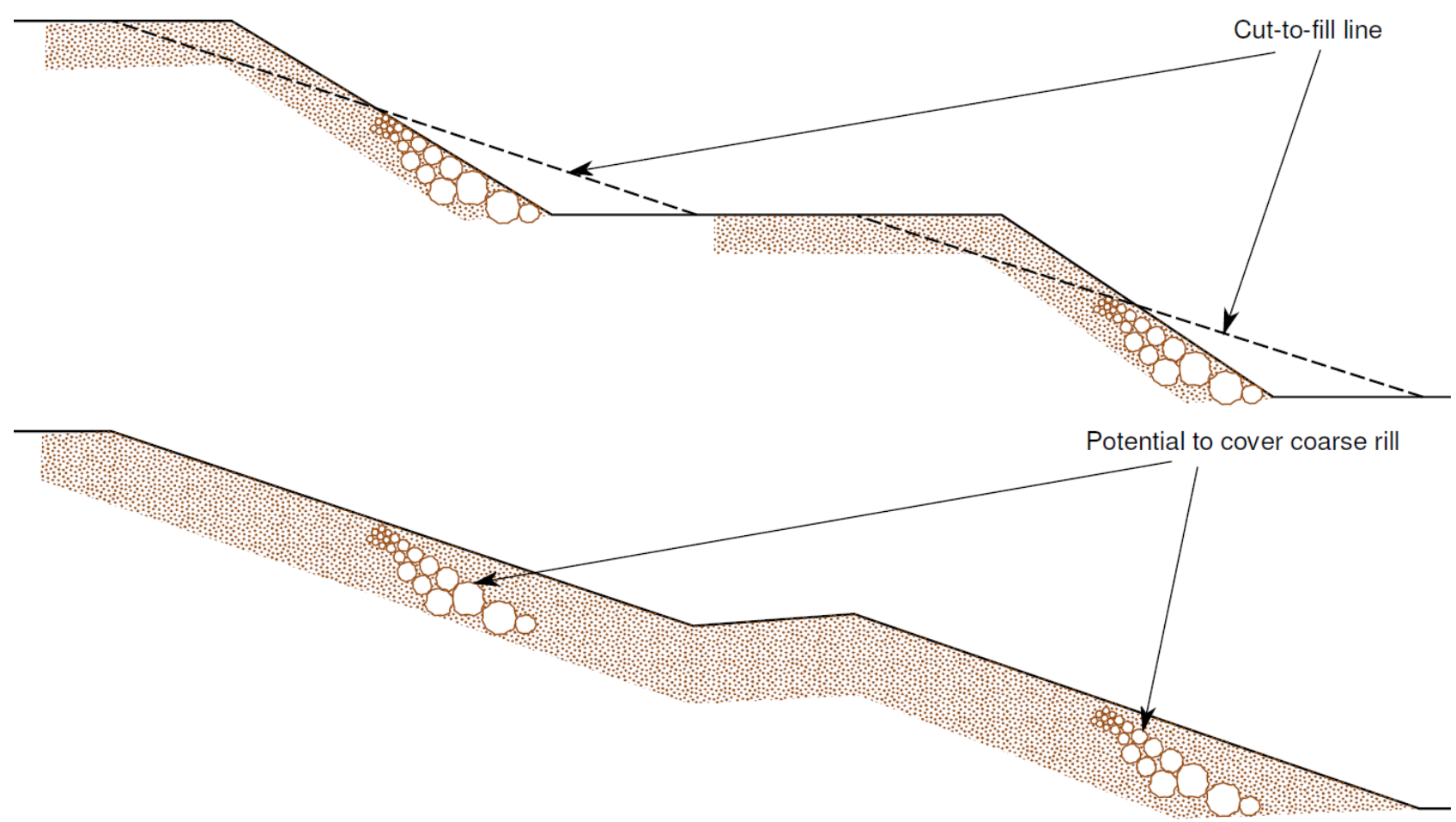

Figure 2 Potential to cover coarse rock with finer rock during WRD batter reprofiling 


\subsection{Petrology/lithology}

How and where a rock was formed will influence its physical properties. There are three main types of rocks: igneous, metamorphic and sedimentary (McGeary et al. 2006).

Igneous rocks are formed from solidification of magma or lava and can be either intrusive or extrusive. Intrusive igneous rocks solidify slowly and are typically coarse grained (e.g. granite), whereas extrusive igneous rocks solidify rapidly and are relatively fine grained (e.g. basalt) (Winter 2010). Igneous rocks exhibit various mineral compositions and can range from very hard to very soft. Igneous rocks can be classified based on their proportion of silica (Table 1). Dolerite, for example, is a mafic, igneous, subvolcanic rock that normally has a fine but visible texture. Dolerites can be soft and friable and can weather very quickly.

Table 1 Classification of igneous rocks based upon silica content (McGeary et al. 2006)

\begin{tabular}{lc}
\hline Igneous rock type & Proportion of silica $\left(\mathrm{SiO}_{2}\right)$ \\
\hline Ultramafic & $<45 \%$ \\
\hline Mafic & $45-52 \%$ \\
\hline Intermediate & $52-63 \%$ \\
\hline Intermediate felsic & $63-69 \%$ \\
\hline Felsic & $>69 \%$ \\
\hline
\end{tabular}

Metamorphic rocks are formed by the transformation of an existing rock type (termed a protolith) via heat and pressure, causing profound physical and/or chemical change (Winter 2010). Metamorphic rocks can exhibit a range of textures, structure and mineral composition.

Sedimentary rocks are formed by the accumulation and deposition of materials at the earth's surface (McGeary et al. 2006). Sedimentary rocks are formed by weathering and erosion and transportation of a source material, and can exhibit a range of textures, structure and mineral composition. Banded iron formations (BIF), for example, are units of sedimentary rocks that consist of repeated layers of iron oxides (magnetite or hematite) alternating with bands of iron-poor shales (fine grained, clastic sedimentary rock) and cherts (fine-grained silica-rich sedimentary rock). BIF and cherts can be very hard and durable.

\section{$2.2 \quad$ Alteration}

Alteration is the mineralogical change in a rock due to invading fluids or the influence of oxygen. Alteration can include chemical weathering at the earth's surface, but mainly refers to hydrothermal alteration which results in rock or mineral phase changes caused by the interaction of hydrothermal fluids and rock (Thompson \& Thompson 1996).

Chlorite for example, is commonly found in igneous rocks as an alteration product of mafic minerals. Chlorite is a sheet silicate, is classified as a clay mineral and has a relatively low hardness rating. Smectite can be an alteration product from chlorite. Smectite is a sheet silicate, is classified as a clay mineral and has a low hardness rating. Smectite exhibits shrink and swell properties which are an important factor for the breakdown of rocks.

\subsection{Mineralogy}

Minerals are pure substances found in nature and rocks are made up of one or more minerals (McGeary et al. 2006). The physical durability of a mineral is controlled by its chemical composition and crystalline structure. Mohs scale of mineral hardness is one useful indicator of rock durability. Mohs scale is based on the ability of one natural sample of mineral to visibly scratch another mineral. 
Table 2 presents the mineralogical results from two rock samples from the mid-west region of Western Australia. The first sample is dolerite (igneous rock) and the second is BIF (sedimentary rock). The two rock types have a different mineralogical composition and the minerals they contain exhibit different hardness values. In this case and based upon mineralogy alone, the BIF exhibits a more durable composition compared with the dolerite.

Table 2 The three most abundant minerals from a dolerite and BIF sample from the mid-west region of Western Australia

\begin{tabular}{lllll}
\hline Rock type & Mineral & Group & Abundance & Hardness (Mohs) \\
\hline Dolerite & Chlorite & Sheet silicate & Dominant-major & $2-2.5$ \\
& Quartz & Framework silicate & Major-minor & 7 \\
& Smectite & Sheet silicate & Minor-accessory & $1-2$ \\
BIF & Quartz & Framework silicate & Major & 7 \\
& Hematite & Oxide & Major & $5.5-6.5$ \\
& Goethite & Oxide & Major & $5-5.5$ \\
\hline
\end{tabular}

\subsection{Weathering}

Weathering involves the breaking down of rocks, soil and minerals through contact with the Earth's atmosphere, biota and waters. The weathering of a rock can influence its durability. How a rock responds to weathering will be influenced in part by its mineral composition and structural characteristics (Scott \& Pain 2009).

A generalised regolith profile is presented in Figure 3. The regolith horizon is the weathered profile of rock overlying bedrock and it consists of pedolith and saprolith zones. The saprolith includes upper saprolite, lower saprolite and saprock horizons (Scott \& Pain 2009).

It is not always the case that the most weathered rocks are the least durable. Silcrete is highly weathered but can be highly durable and porous with a high water holding capacity. 


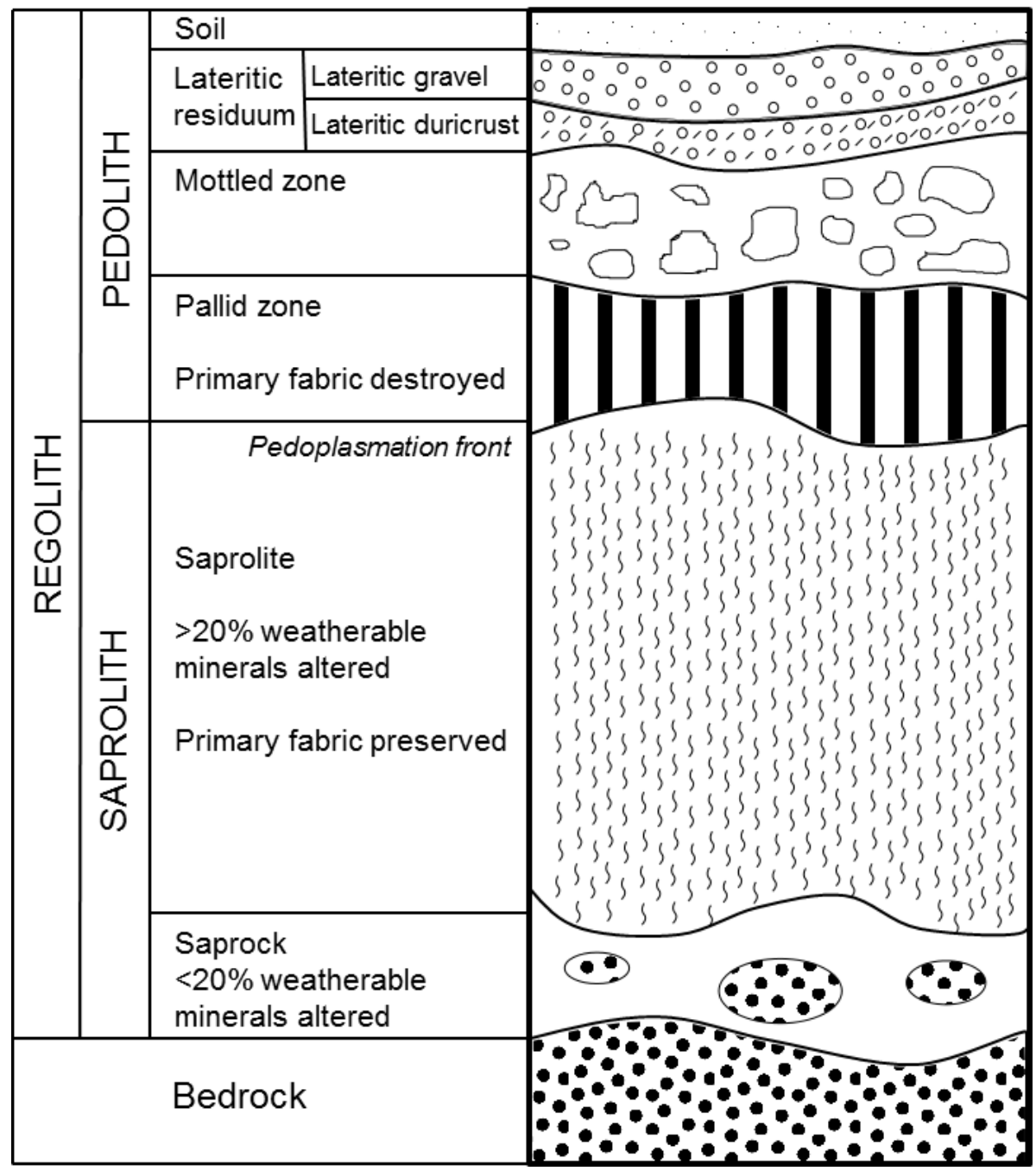

Figure 3 Generalised regolith profile (after McQueen \& Scott 2009)

\subsection{Structural deformation}

Deformation refers to the structural changes that occur in the location, orientation, shape and volume of a body or rock. Structural deformation results from stresses that exceed rock strength; when rock strength is exceeded, rock will fail by brittle (fracture) or ductile (flow) deformation, depending upon the ability of the rock to resist the stresses. Deformation can result in regional scale structures (mountain building), local scale structures (folding, faulting, shearing), down to micro scale structures (mineral crystal scale) (Davis \& Reynolds 1996).

The deformation history of a rock will influence its physical properties. For example a dolerite rock may exhibit a strongly foliated texture (penetrative planar fabric) as a result of strain and folding. A foliated dolerite rock will be less durable and more prone to weathering and deterioration than a massive (unfoliated) dolerite of the same composition.

\subsection{Summary}

The geological factors that control the physical properties of rock and interactions between each factor can be complex. A siltstone for example is a sedimentary rock which may exhibit poor stability properties and be susceptible to erosion. If subjected to siliceous alteration, however, siltstones can be very durable and resistant to erosion. On the other hand, a BIF is also a sedimentary rock, typically with inherently good stability properties (durable and competent). If subjected to brittle deformation, however, BIF rocks can be susceptible to erosion. 


\section{Techniques to assess the physical properties of rock}

Routine soil science techniques are currently being applied to predict and assess the physical properties of mine waste in Western Australia, mainly to assess the susceptibility of rock to erosion. Some of the common tests are described in Table 3.

Table 3 Common techniques to assess mine waste physical properties in Western Australia

\begin{tabular}{|c|c|}
\hline Test & Description \\
\hline $\begin{array}{l}\text { Emerson dispersion } \\
\text { test (EDT) }\end{array}$ & $\begin{array}{l}\text { Aggregate slaking and dispersion test to assess aggregate strength (soil structure) } \\
\text { (classes } 1 \text { [poor] to } 8 \text { [good]). } \\
\text { Test performed on }<2 \mathrm{~mm} \text { fraction. }\end{array}$ \\
\hline $\begin{array}{l}\text { Modulus of rupture } \\
\text { (MOR) }\end{array}$ & $\begin{array}{l}\text { Identifies tendency of a soil to hard-set and measures strength in relation to plant } \\
\text { growth (values }>60 \mathrm{kPa} \text { are poor). } \\
\text { Test performed on }<2 \mathrm{~mm} \text { fraction. }\end{array}$ \\
\hline $\begin{array}{l}\text { Particle size } \\
\text { distribution (PSD) }\end{array}$ & $\begin{array}{l}\text { Presence and relative abundance of sand, silt and clay particles. } \\
\text { Test performed on }<2 \mathrm{~mm} \text { fraction. }\end{array}$ \\
\hline Soil texture & $\begin{array}{l}\text { Describes the particle size distribution and resulting textural class of a soil. } \\
\text { Test performed on }<2 \mathrm{~mm} \text { fraction. }\end{array}$ \\
\hline $\begin{array}{l}\text { Saturated } \\
\text { conductivity (Ksat) }\end{array}$ & $\begin{array}{l}\text { Measures permeability or the ability of water to infiltrate. } \\
\text { Test performed on }<100 \mathrm{~mm} \text { fraction. }\end{array}$ \\
\hline $\begin{array}{l}\text { Water retention } \\
\text { characteristics/water } \\
\text { holding capacity } \\
\text { (WHC) }\end{array}$ & $\begin{array}{l}\text { The capacity of soil to accept and store water. } \\
\text { Test performed on }<2 \mathrm{~mm} \text { fraction. }\end{array}$ \\
\hline Exchangeable cations & $\begin{array}{l}\text { Positively charged ions which are loosely attached to the edge of clay particles or } \\
\text { organic matter in the soil including calcium, magnesium, sodium and potassium. } \\
\text { If } \mathrm{Ca}, \mathrm{Mg} \text { and } \mathrm{K} \text { are dominant on the clay exchange surfaces, soil may be stable. } \\
\text { If } \mathrm{Na}>6 \% \text {, soil is sodic and can be erosive (dispersive and hard-setting). }\end{array}$ \\
\hline $\begin{array}{l}\text { Exchangeable sodium } \\
\text { percentage (ESP) }\end{array}$ & $\begin{array}{l}\text { If ESP }>15 \% \text {, soil is considered highly sodic. Sodic soils are prone to disperse when } \\
\text { wet and are prone to hard-setting. }\end{array}$ \\
\hline $\begin{array}{l}\text { Effective cation } \\
\text { exchange capacity } \\
\text { (eCEC) }\end{array}$ & $\begin{array}{l}\text { Detrimental influence of high sodicity may be limited by eCEC. High eCEC } \\
\text { indicates greater presence of sodium ions and a higher potential for sodicity } \\
\text { to influence clay dispersion. }\end{array}$ \\
\hline Simulated rainfall & $\begin{array}{l}\text { Flumes where overhead reticulation is applied to measure interrill erosion; } \\
\text { sediment loads are recorded to derive erodibility parameters, runoff rates are } \\
\text { recorded to derive effective hydraulic conductivity. } \\
\text { Test performed on }<100 \mathrm{~mm} \text { fraction. }\end{array}$ \\
\hline $\begin{array}{l}\text { Concentrated surface } \\
\text { flows }\end{array}$ & $\begin{array}{l}\text { Flumes where overland flow is applied; rill and sediment characteristics are } \\
\text { recorded and used to derive critical shear and rill erodibility. } \\
\text { Test performed on }<100 \mathrm{~mm} \text { fraction. }\end{array}$ \\
\hline $\begin{array}{l}\text { Water Erosion } \\
\text { Prediction Project } \\
\text { (WEPP) }\end{array}$ & $\begin{array}{l}\text { WEPP models slope angles and heights and predicts erosion rates for different } \\
\text { rock types. Erodibility is described via interrill erodibility, rill erodibility, critical } \\
\text { shear for rill initiation and effective hydraulic conductivity. }\end{array}$ \\
\hline
\end{tabular}

Some of the tests listed in Table 3 are undertaken on the $<2 \mathrm{~mm}$ (fines) fraction of the sample and others are undertaken on the $<100 \mathrm{~mm}$ fraction. In the field, however, a large portion of dumped rock on a waste 
rock dump (WRD) may comprise $>2 \mathrm{~mm}$ (up to $100 \%$ ) and $>100 \mathrm{~m}$ (up to $70 \%$ ) rock fraction. In this instance, the results from testwork on the $<2 \mathrm{~mm}$ or $<100 \mathrm{~mm}$ fraction would not be representative and could not be readily applied to predict field conditions.

Typically, a sample is sieved to obtain the $<2 \mathrm{~mm}$ fraction and in some cases where insufficient fines are available, samples can be crushed to generate the required fraction. Fragments $>100 \mathrm{~mm}$ are generally excluded during sample collection.

\section{$4 \quad$ Effectiveness of current techniques}

Some of the techniques currently employed to assess the physical properties of mine waste can be unreliable in predicting the erosion potential of rock. Working examples are presented below.

\subsection{Case study 1}

In an example from Western Australia, a mining company was recently awarded approval to develop a project with a detailed mine waste characterisation study that predicted only that $2 \%$ of the mine waste volume would be potentially acid forming (PAF) and that all mine waste would be durable and competent and suitable for construction of WRD slopes.

The authors were asked to review the findings of the mine waste characterisation study (which was undertaken by others), and by applying basic geological knowledge it was identified that: the factors that controlled the distribution of PAF were largely unknown; and that the extensive weathered profile coupled with friable primary lithologies would likely result in erosive mine waste.

A subsequent targeted baseline assessment identified that most mine waste (approximately 70\%) was predicted to be PAF and that most mine waste would be highly erosive. These predictions were verified during the operating phase and had significant consequences for the project.

\subsection{Case study 2}

In a second example from Western Australia, a mining company completed a detailed baseline mine waste characterisation study across three mines. Based upon testwork outcomes the study predicted that most mine waste would be durable and competent. What was observed during mining was in some cases very different and a large proportion of mine waste was found to be highly erosive.

The authors were asked to review the findings of the baseline study (which was undertaken by others) to determine why it failed to accurately predict the as-dumped physical properties of mine waste. In this case, the routine soil science tests that were applied to rock samples were not able to predict as-dumped stability properties. Data is presented below on one sample from the original baseline study to demonstrate this point.

One rock sample from the baseline study had the following properties:

- Emerson class 3b (slaked and partial dispersion).

- $\mathrm{MOR} 3.1 \mathrm{kPa}$ (>60 is poor).

- $\operatorname{ESP} 12 \%$ (> $15 \%$ is high).

These results indicated that the sample should be reasonably durable and, based upon the results, the study found that mine waste should consist of competent rock that has undergone limited weathering and that erosion should not become an issue.

During mining and construction of the WRD, it was identified that most mine waste was friable and erosive as shown in Figure 4. As a result, a large proportion of the WRD will require rock armouring at closure to achieve acceptable long-term stability outcomes. 
Basic geological observation and interpretation would have been able to identify that the mine waste zones were likely to be friable. Figure 5 shows the core tray from which the sample described above was collected. It can be seen that the rock in this core tray is highly fragmented and friable, would have a low rock-quality designation (RQD) rating $(<50 \%$ of core in continuous lengths $>10 \mathrm{~cm})$, and would very likely produce low stability rock during mining.

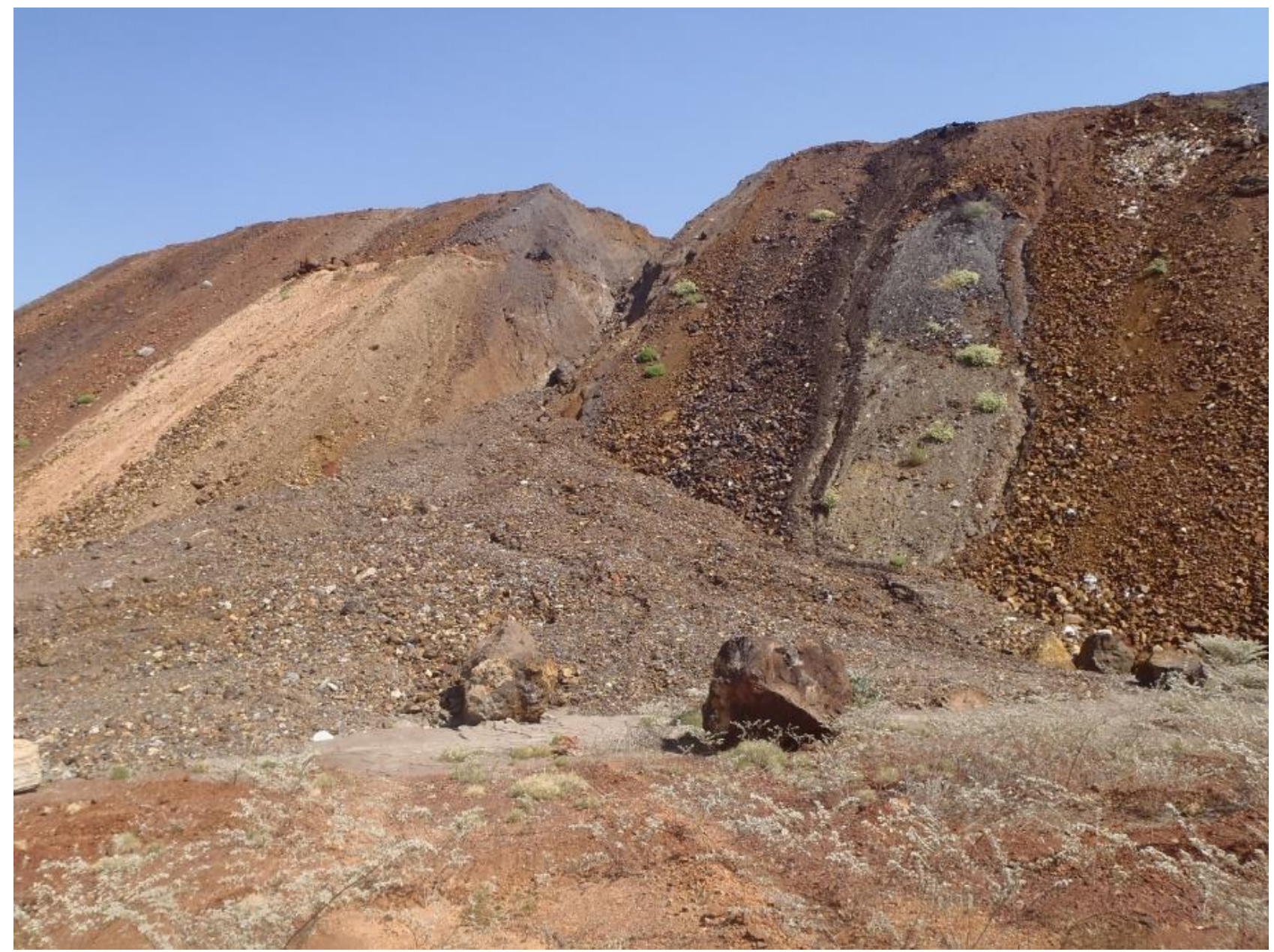

Figure 4 Erosive rock from a WRD where durable rock was predicted (Case study 2)

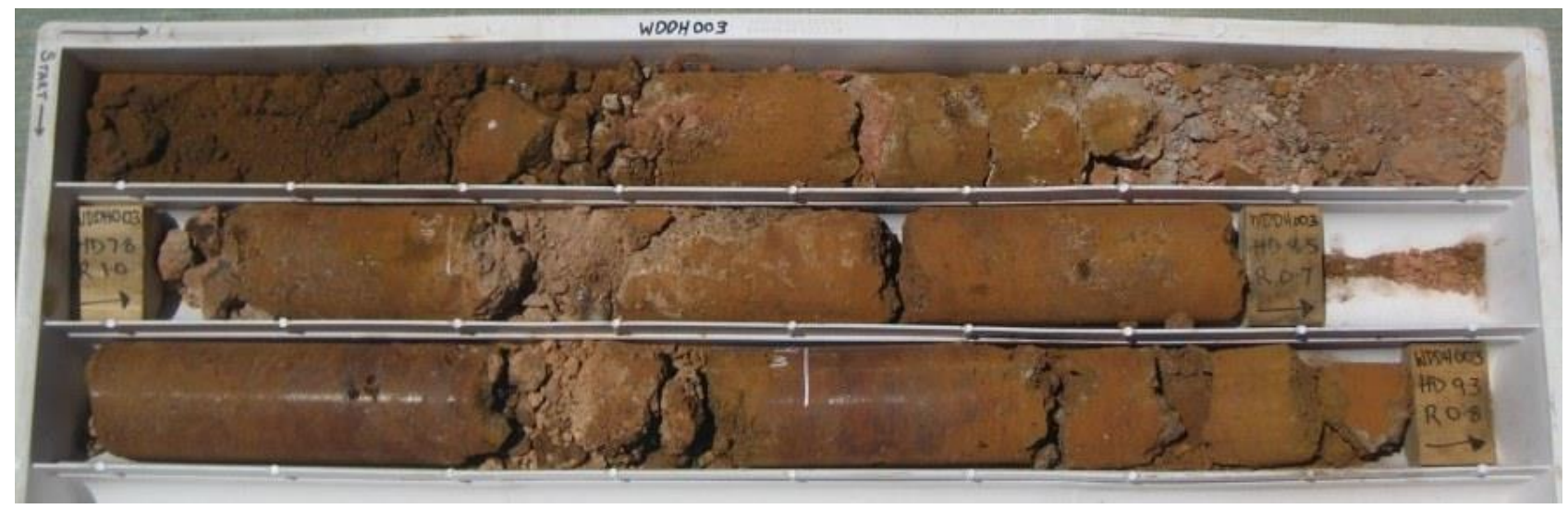

Figure 5 Core tray from which sample described in Case study 2 was collected 


\subsection{Statistical analysis}

Multivariate statistical analysis of results from as-dumped mine waste from two Western Australian mines was undertaken using Principal Components Analysis (PCA). PRIMER (Version 6) software was used to analyse the results. Ordination of the data was performed using PCA to assess similarities between the data (Clarke \& Gorley 2006).

PCA produces a plot on which data with similar characteristics are grouped close together, while those with different characteristics are located further apart. Vectors on the plot represent the influence of the different parameters on the data set. The longer the vectors the greater the influence on the data set (Clarke \& Gorley 2006).

Figure 6 presents PCA results from a comparison between the stability class of as-dumped mine waste derived from geological mapping (high, moderate, low stability), and corresponding EDT, ESP and eCEC results from the mapped stability zones. We can see that there is no correlation between the results from commonly accepted testwork and actual as-dumped rock stability properties.

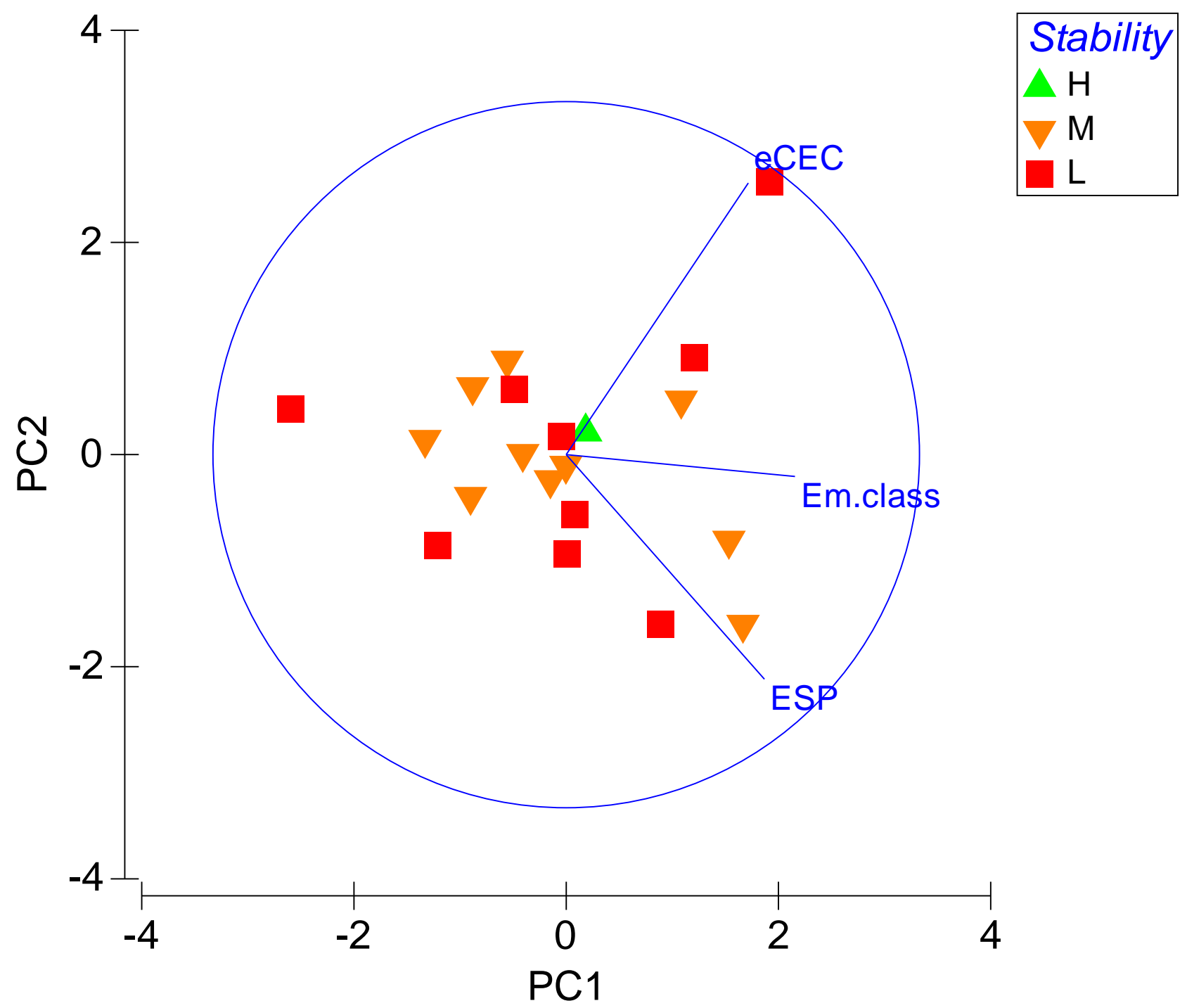

Figure 6 PCA graph comparing rock stability class from geological mapping and EDT (Em.class), ESP and eCEC results from relevant geozones

Figure 7 presents PCA results from a comparison between the stability class and coarse particle size distribution (PSD) results (also derived from geological mapping) from the mapped stability zones. It can be seen that there is a positive correlation between coarse PSD and stability class. For example, those samples 
with a low stability class were grouped together on the plot and typically had higher proportions of $<2 \mathrm{~mm}$ particles in comparison with the medium and high stability class samples which had a greater proportion of fragments greater than $100 \mathrm{~mm}$. Figure 7 shows that geological observation can be a better indicator of waste rock stability than some commonly accepted testwork methods.

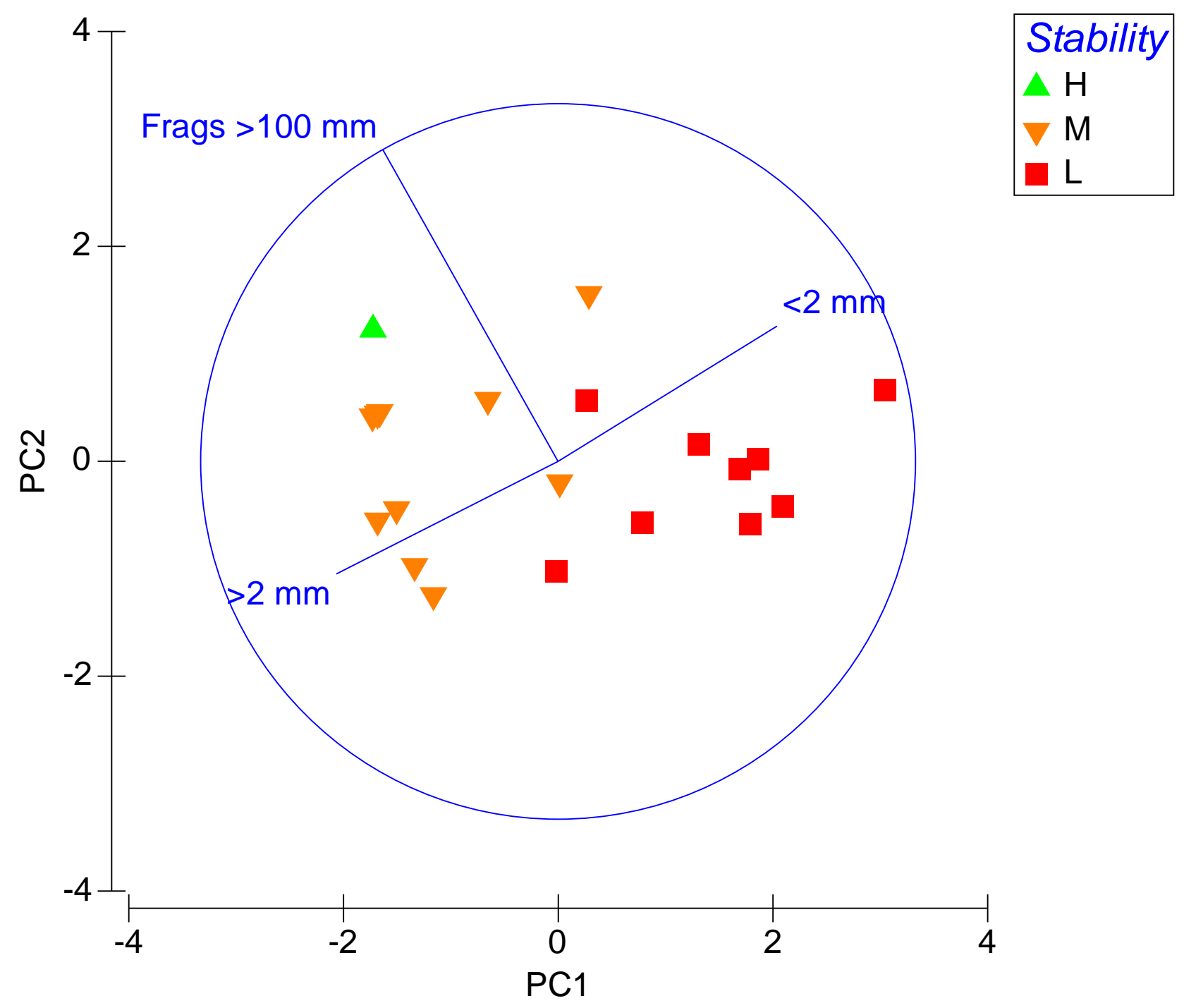

Figure 7 PCA graph comparing rock stability class from geological mapping and coarse PSD results from geological mapping $(<2 \mathrm{~mm} ;>2 \mathrm{~mm}$; fragments $>100 \mathrm{~mm})$

\subsection{Weathering rates}

Current testwork techniques assess the properties of rock at a fixed point, typically with little consideration that rock will weather and deteriorate over time and that different rock types can exhibit very different weathering characteristics. By way of example, Figure 8 illustrates two rocks from the same WRD that were dumped at a similar time. One rock appears durable and competent (BIF) and the other has deteriorated completely (foliated dolerite), despite being placed on the WRD as a competent fragment. Interestingly, the competent BIF came from higher in the weathered profile (oxide) than the dolerite (transitional). 


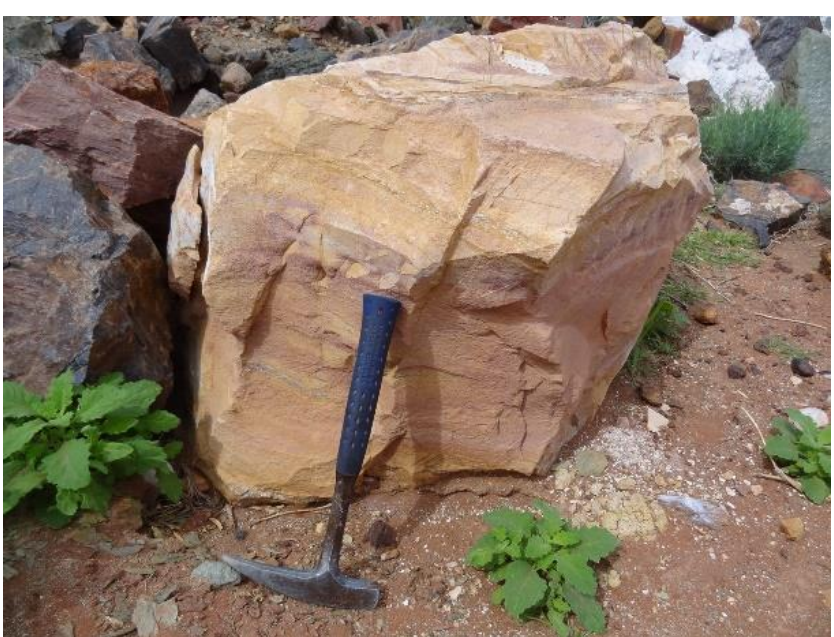

(a)

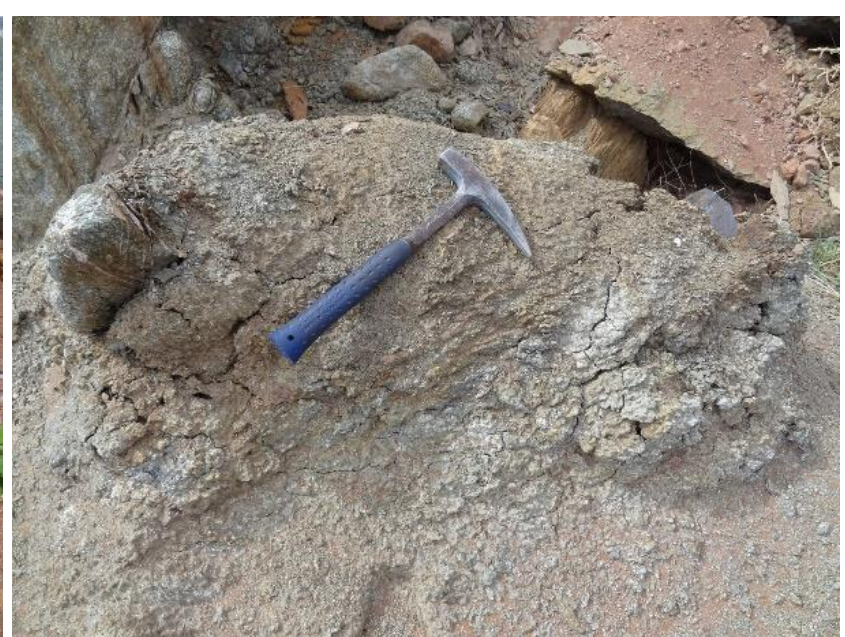

(b)

Figure 8 Two rocks from the same WRD dumped at a similar time exhibiting very different weathering properties; (a) BIF and (b) dolerite

\section{Sample selection}

With current techniques, mine waste samples are often collected in geological isolation, and without due regard to the factors that control stability. Samples are often selected by mine site personnel and sent to a laboratory.

For example, Dolerite might be a key rock type that requires assessment and a sample may be sent to a laboratory for testwork and interpretation. But how representative will that sample be of the dolerite overall? Will different zones of the dolerite exhibit differing physical properties based upon the geological factors that control stability? Consider that there may be fresh, transitional and oxidised dolerite, massive or structurally deformed dolerite (folidated, folded), or altered dolerite proximal to the mineralised zone (silicified). These factors will all influence the physical properties of the dolerite. Geological mapping and identification of geo-zones based upon all of the factors that control stability is essential before a targeted sampling program can be developed.

For baseline mine waste assessments prior to mining, it is very difficult to collect samples that will be representative of as-dumped rock. All that can be accessed is drill samples (RC chips or diamond drill core) and most testwork on drill samples will be ineffectual.

\section{Alternative approach}

An alternative approach for assessing and predicting the stability properties of mine waste for greenfields and brownfields mining projects is presented below.

\subsection{Greenfields assessment}

Our approach to a greenfields project or baseline assessment includes the following steps:

1. Define geological zones (geo-zones) based upon likely physical (and geochemical) properties of rock. Liaise with project geologists to develop a working understanding of deposit geology including lithology, alteration, mineralogy, weathering and structure.

2. Utilise the resource model to calculate relative waste rock volumes from key geo-zones (example provided in Table 4), and to determine the timing of key geo-zones in terms of the mining sequence. 
3. Develop a sampling program that targets representative samples from each geo-zone, from along strike and down dip of the deposit. Sample numbers to be defined from the relative abundance of geo-zones and associated risk.

4. Undertake appropriate testwork to verify geological predictions. Very little useful physical testwork can often be undertaken from drill samples; the focus should be on targeted testwork to verify geological predictions.

5. Testwork should be selected from an assessment of the geological factors that control rock stability. For example, whole rock mineralogy might be assessed if mineral composition was the dominant geological factor, whereas a visual assessment of RQD might be undertaken if structural features were the dominant factor.

6. Develop preliminary mine waste management recommendations and associated conceptual landform (WRD) design guidance.

7. Verify predictions' once mining commences and access is available to inspect and sample (if required) as-dumped rock.

Table 4 Stability classification and volumetric assessment by rock type from two gold deposits in the Goldfields region of Western Australia

\begin{tabular}{lcc}
\hline Rock type & Relative proportion (\%) & Rock stability classification \\
\hline Quartzite & 12 & High \\
\hline $\begin{array}{l}\text { Carbonaceous shale } \\
\text { (above water table) }\end{array}$ & 20 & Moderate \\
\hline $\begin{array}{l}\text { Carbonaceous shale } \\
\text { (below water table) }\end{array}$ & 11 & Low \\
\hline Main BIF & 33 & Moderate \\
\hline Chert/shale & 10 & Low \\
\hline Upper BIF & 14 & Moderate \\
\hline Total & 100 & \\
\hline
\end{tabular}

\subsection{Brownfields assessment}

Our approach to a brownfields project or ex situ assessment includes the following steps:

1. Map the as-constructed WRD to define geo-zones based upon geological properties. Divide the WRD into stability zones (example provided in Figure 9). Develop a working understanding of deposit geology including lithology, alteration, mineralogy, weathering and structure.

2. Use the resource model to calculate relative waste volumes from key geo-zones and timing in terms of the mining sequence. This will help determine the distribution of geo-zones on and within the WRD.

3. Develop a sampling program to collect waste rock samples that are representative of each geo-zone. Sample numbers to be defined from the relative abundance of geo-zones and associated risk.

4. Undertake appropriate testwork to verify geological observations and predictions. Some useful testwork can be undertaken from as-dumped samples, but testwork should be focussed. 
5. Testwork should be selected from an assessment of the factors that control rock stability. For example, PSD, Atterberg limits and clay mineralogy might be assessed if as-dumped rock had a high proportion of fines ( $<2 \mathrm{~mm}$ fraction).

6. Develop a conceptual closure design for the WRD based upon as-constructed form, waste rock properties and hydrological assessment outputs.

7. Confirm waste rock properties after WRD reprofiling.

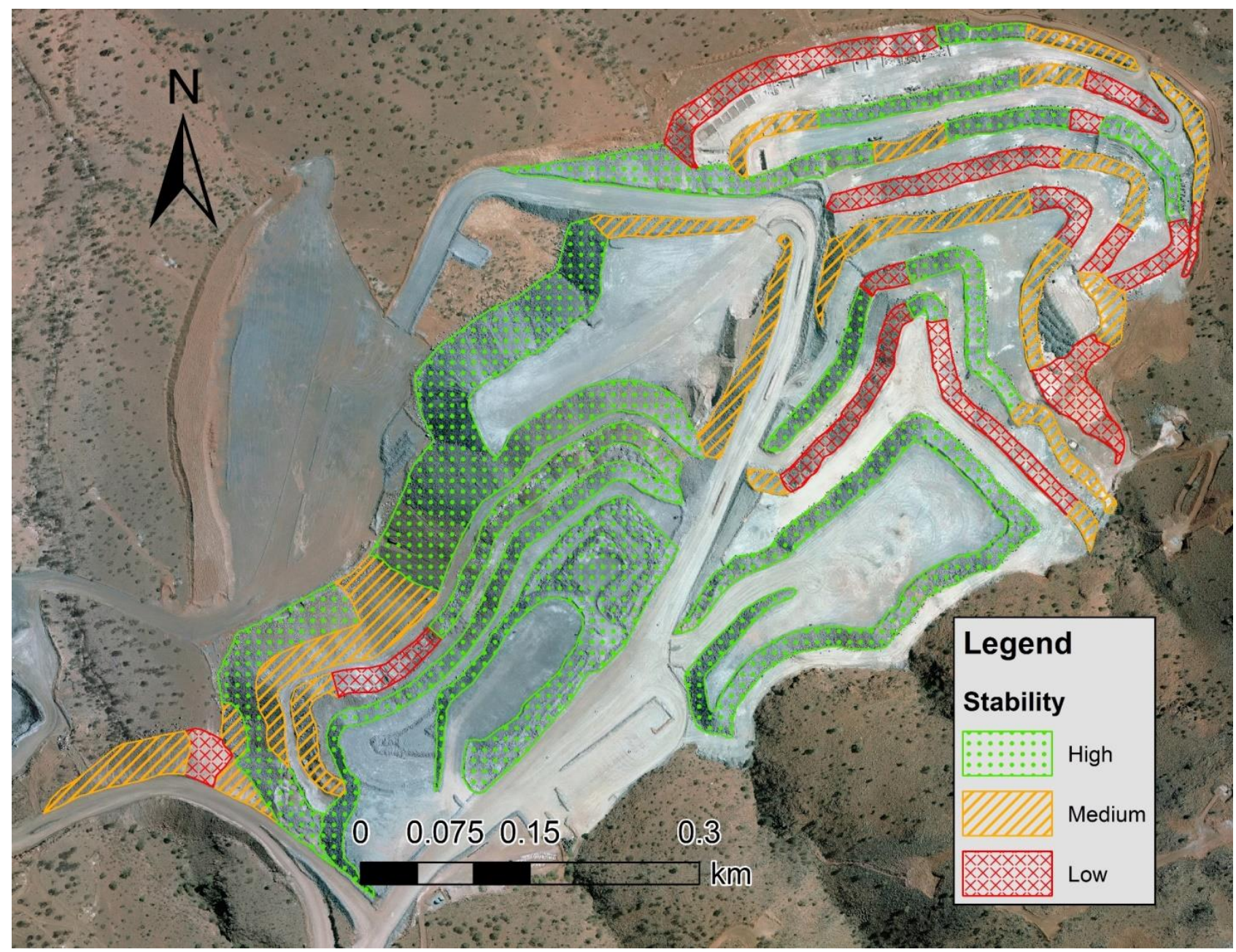

Figure 9 Geological mapping and waste rock stability assessment for an as-constructed WRD in Western Australia

\section{Conclusion}

Mine waste characterisation aims to predict the geochemical and physical properties of rock to identify deleterious or beneficial materials, and use this information to inform closure designs for mining landforms.

Some commonly accepted soil science techniques assess the resultant properties of rock, without considering the factors that control those properties, and can be unreliable in predicting erosion potential of rock. Furthermore, mine waste sampling programs are not always developed from a working understanding of deposit geology and from interpretation of complex geological information.

The geological factors that control rock stability and the interplay between these factors can be complex. Geological observation and interpretation must be applied to assessments of rock. Such assessments are relatively cheap and are most effective in assessing the erosion potential of rock. 


\section{References}

Clarke, KR \& Gorley, RN 2006, Primer V6: User Manual/Tutorial, PRIMER-E. Ltd, Plymouth.

Davis, GH \& Reynolds, SJ 1996, Structural geology of rocks and regions, Second edition, John Wiley \& Sons Inc.

McGeary, D, Carlson, DH \& Plummer, CC 2006, Physical Geology, Seventh Edition, McGraw-Hill Higher Education.

McQueen, KG \& Scott, KM 2009, 'Rock weathering and structure of the regolith', in KM Scott \& CF Pain (eds), Regolith Science, CSIRO Publishing, Australia, pp. 105-126.

Scott, KM \& Pain, CF 2009, Regolith science, CSIRO Publishing.

Smedley, E, Mackenzie, S, Astill, W, Campbell, G \& Haymont, R 2014, 'Cost effective integrated assessment of mine waste and practical management solutions', paper presented at the Goldfields Environmental Management Group conference in Kalgoorlie WA, May 2014.

Thompson, AJB \& Thompson, JFH (eds) 1996, Atlas of alteration - a field and petrographic guide to hydrothermal alteration minerals, Geological Association of Canada, Mineral Deposits Division.

Winter, JD 2010, An introduction to igneous and metamorphic petrology, Second edition, Pearson Education Inc. 